US Army Corps

of Engineers ${ }_{\circledast}$

Engineer Research and

Development Center

Photo Degradation Kinetics of Insensitive Munitions Constituents Nitroguanidine, Nitrotriazolone, and Dinitroanisole in Natural Waters

Lee C. Moores, Stacy J. Jones, Garrett W. George, September 2021

David L. Henderson, and Timothy C. Schutt 
The U.S. Army Engineer Research and Development Center (ERDC) solves the nation's toughest engineering and environmental challenges. ERDC develops innovative solutions in civil and military engineering, geospatial sciences, water resources, and environmental sciences for the Army, the Department of Defense, civilian agencies, and our nation's public good. Find out more at www.erdc.usace.army.mil.

To search for other technical reports published by ERDC, visit the ERDC online library at https://erdclibrary.on.worldcat.org/discovery. 


\section{Photo Degradation Kinetics of Insensitive Munitions Constituents Nitroguanidine, Nitrotriazolone, and Dinitroanisole in Natural Waters}

Lee C. Moores, Garrett W. George, David L. Henderson, and Timothy C. Schutt

Environmental Laboratory

U.S. Army Engineer Research and Development Center

3909 Halls Ferry Road

Vicksburg, MS 39180

Stacy J. Jones

HX5

212 Eglin Parkway SE

Ft. Walton Beach, FL 32548

Final report

Approved for public release; distribution is unlimited.

Prepared for U.S. Army Corps of Engineers

Washington, DC 20314

Under Environmental Quality and Technology Program 


\section{Preface}

This project was supported by the U.S. Army Corps of Engineers (USACE) under the Environmental Quality and Technology Program and Engineer Research and Development Center (ERDC) WIC H2735L.

The work was performed by the Army's Engineer Research and Development Center, Environmental Laboratory (ERDC-EL). At the time of publication of this paper, the Deputy Director of ERDC-EL was Dr. Brandon Lafferty and the Director was Dr. Edmund J. Russo Jr.

This article was originally published online in the Journal of Photochem istry \& Photobiology A: Chemistry on 17 September 2019.

The Commander of ERDC was COL Teresa A. Schlosser and the Director was Dr. David W. Pittman.

DISCLAIMER: The contents of this report are not to be used for advertising, publication, or promotional purposes. Citation of trade names does not constitute an official endorsement or approval of the use of such commercial products. All product names and trademarks cited are the property of their respective owners. The findings of this report are not to be construed as an official Department of the Army position unless so designated by other authorized documents. 


\title{
Photo degradation kinetics of insensitive munitions constituents nitroguanidine, nitrotriazolone, and dinitroanisole in natural waters
}

\begin{abstract}
A B S T R A C T
Herein the matrix effects on the kinetics of aqueous photolysis for the individual munitions constituents of IMX101: nitroguanidine (NQ), dinitroanisole (DNAN), and nitrotriazolone (NTO) are reported along with the environmentally relevant kinetics and quantum yields. Photolysis potentially represents a major degradation pathway for these munitions in the environment and further understanding the complex matrices effects on photolytic kinetics was needed. Aqueous systems are of particular interest due to the high solubility of NQ (3,800 ppm) and NTO (16,642 ppm) compared to the traditional munitions trinitrotoluene (TNT, $100.5 \mathrm{ppm})$ and 1,3,5-trinitro-1,3,5-triazine (RDX, $59.9 \mathrm{ppm}$ ). Environmental half-lives (and quantum yields) were found to be 0.44 days $\left(1.0 \times 10^{-2}\right), 0.83$ days $\left(3.2 \times 10^{-4}\right)$, and 4.4 days $\left(5.9 \times 10^{-5}\right)$ for NQ, DNAN, and NTO, respectively, under natural sunlight. In laboratory experiments using nominally $300 \mathrm{~nm}$ bulbs in a merry-go-round style reactor in DI water the relative rate of photolysis for the three munitions constituents followed the same order NQ > DNAN > NTO, where DNAN and NTO reacted 57 and 115 times more slowly, respectively, than NQ. In the various environmentally relevant matrices tested in the laboratory experiments NQ was not significantly affected, DNAN showed a faster degradation with increasing ionic strength, and NTO showed a modest salinity and $\mathrm{pH}$ dependence on its rate of photolysis.
\end{abstract}

\section{Introduction}

Increasing soldier safety by mitigating unintended detonation of munitions by replacing legacy munitions, such as trinitrotoluene (TNT) and 1,2,3-trinitro-1,3,5-triazine (RDX), with insensitive munitions has been underway for numerous years [1]. Insensitive Munition eXplosive, IMX-101, is a mixture of nitroguanidine (NQ), 2,4-dinitroanisole (DNAN), and 5-nitro-1,2,4-triazol-3-one (NTO), which exhibits decreased shock sensitivity when compared to legacy munitions. Environmental fate concerns of the constituents are partially based on the aqueous solubility of NQ and NTO being 33.8 and 165.6 times more soluble than TNT, respectively [2,3]. Initial toxicity assays showed both of these constituents to be relatively nontoxic, particularly when the NTO was buffered to circumneutral pH $[4,5]$. DNAN is only slightly more soluble than TNT (2.75 times) and shows a reduced toxicity compared to TNT both before and after photolysis [3,4].

Issues have arisen during subsequent toxicity studies showing the mixture, IMX-101, to increase in toxicity upon exposure to environmentally relevant UV light where the photolyzed mixture has roughly equivalent toxicity to photolyzed TNT [4,6]. The increased toxicity was found to be due primarily to the NQ component, whereas the NTO and DNAN exhibited modest increases in toxicity. Further studies in the photolysis of these munition constituents focused mainly on the degradation product identification [7-15], with only four detailed reports on the kinetics and quantum yields of the constituents' photolysis [12-15]. To understand and better predict the environmental fate of the munitions we sought to determine the environmental half-lives and elucidate the matrix effects these munitions are likely to encounter in aqueous environments.

Although standard methodologies do make use of natural organic matter, which behaves as a triplet sensitizer to induce photolysis, and $\mathrm{pH}$ for molecules readily ionized under environmental conditions, they do not account for ionic strength. The $\mathrm{pH}$ of the solution could exhibit effects on molecules susceptible to nucleophilic substitution, which do not have sufficiently appreciable $\mathrm{pKa}$ values to warrant $\mathrm{pH}$ adjustments, such as nitro aromatics [16-18]. The photolytic rate for TNT has also been shown to be directly correlated with ionic strength [19]. With these examples in mind, all munition constituents were tested in 
environmentally relevant aqueous mixtures for photolytic activity and quantum yields.

\section{Methods and materials}

\subsection{Reagents}

All reagents were used as received. NQ (containing $25 \% \mathrm{H}_{2} \mathrm{O}$ as a stabilizer), Pyridine ( $\geq 99.9 \%$ ), and 4-nitroacetophenone (98\%), sodium phosphate monobasic dihydrate $(\geq 99.9 \%)$, sodium acetate (>99\%), boric acid (99.9999\%), humic acid sodium salt (batch number 02022PA) were obtained from Sigma Aldrich. DNAN (98\%) was obtained from Alfa Aesar. NTO (military grade) was obtained from BAE Systems. Trifluoroacetic acid (Optima HPLC grade) was obtained from Thermo Scientific. Acetonitrile (HPLC grade), methanol (HPLC grade), sodium chloride (99.8\%), and sodium hydroxide (98\%) were obtained from Fisher Scientific. NQ standards were obtained from Restek and DNAN and NTO standards were made from the chemicals listed above. Any water used throughout the experiment was purified by a Milli Q water purification system giving a resistivity of $>18.2 \mathrm{M}$ $\Omega \mathrm{cm}$.

\subsection{Instrumentation}

An Agilent Cary-8454 UV-vis was used for determining molar absorption coefficients in quartz cuvettes. An Agilent 1200 Series HPLC system equipped with a quaternary pump, Agilent 1200 Series Diode Array Multiple Wavelength Detector, and Synergi $4 \mu \mathrm{m}$ Hydro-RP $80 \AA$ C18 with polar end-capping column $(250 \times 4.6 \mathrm{~mm}$; Phenomenex $)$ was used for sample analysis. Bruker Daltonics Data Analysis software was used for peak integrations. Each munition required a separate HPLC method; however, all injection volumes were $50 \mu \mathrm{L}$ and all mobile phases were isocratic. For NQ (ret time $=4 \mathrm{~min}$ ), the mobile phase was $100 \%$ water at a flow rate of $1.1 \mathrm{~mL} / \mathrm{min}$. For DNAN (ret time $=14.6$ $\mathrm{min}$ ), the mobile phase consisted of $55-45-5 \%$ water-acetonitrile- aqueous trifluoracetic acid $(0.1 \% \mathrm{v} / \mathrm{v})$ at a flow rate of $1.1 \mathrm{~mL} / \mathrm{min}$. For NTO (ret time $=3.9 \mathrm{~min}$ ) the mobile phase consisted of $85-10-5 \%$ wateraqueous trifluoracetic acid $(0.1 \% \mathrm{v} / \mathrm{v})$-acetonitrile at a flow rate of $1.1 \mathrm{~mL} / \mathrm{min}$. For PNAP (ret time $=3.85 \mathrm{~min}$ ), the mobile phase was $25-75 \%$ water-methanol at a flow rate of $1.1 \mathrm{~mL} / \mathrm{min}$.

\subsection{Preparation of solutions}

NQ, DNAN, and NTO were dissolved separately in water to make stock solutions. The concentrations were confirmed by HPLC with the respective calibration curves: NQ from commercial standard, DNAN from pure solid, and NTO from the military grade solid. Representative calibration curves for the 3 munitions (Fig. S4-6) were linear over the ranges tested $(0.01-20 \mathrm{ppm}$ for NQ, $0.1-100 \mathrm{ppm}$ for DNAN, and $0.025-50 \mathrm{ppm}$ for NTO). These solutions were sufficiently concentrated such that the volume added to the various matrices, preparation described below, would comprise less than $1 \%$ of the final volume in the different matrices (i.e. [IMs] > $100 \mathrm{ppm}$ ). The p-nitroacetophenonepyridine (PNAP-PYR) actinometer was used for quantum yield calculations. Three separate PNAP-PYR solutions were prepared, one for each munition. The concentration of PNAP was $10 \mu \mathrm{M}$ for each munition's actinometer. The concentration of pyridine in each actinometer was calculated based on the corresponding munition's half-life. These calculations as well as the actinometer preparation are outlined in standard methodology [20]. Pyridine concentrations for NQ, DNAN, and NTO were $0.04655 \mu \mathrm{M}, 0.0570 \mu \mathrm{M}$, and $0.0395 \mu \mathrm{M}$, respectively.

Moderately Hard Reconstituted Water (MHRW) was prepared in accordance with standard methods [21]. Artificial seawater was prepared from Crystal Sea Marine Mix Salt in accordance to bioassay standards and had a conductivity of $25.93 \mathrm{mS} / \mathrm{cm}$. The brackish water was prepared by mixing equal volumes of artificial seawater and
MHRW and had a conductivity of $12.89 \mathrm{mS} / \mathrm{cm}$. Humic acid solutions were prepared in accordance with EPA method 835.5270 and measured to be $5 \mathrm{ppm}$ by UV-vis analysis and $3.33 \mathrm{ppm}$ by TOC analysis to find the organic matter to be roughly $67 \%$ carbon. Acetate, phosphate, and borate ( $\mathrm{pH} \mathrm{4,7}$, and 10, respectively) were prepared in accordance with The Handbook of Chemistry and Physics [22].

\subsection{Laboratory photolysis experiments}

Laboratory photolysis studies were conducted inside a Rayonet Photochemical Reactor (Southern New England Ultraviolet Co., Model RPR-1000) equipped with sixteen $14 \mathrm{~W}$ bulbs emitting primarily at $300 \mathrm{~nm}$ (RPR-3000A, Fig. S3) where the samples were rotated in a carrousel (RMA-500) revolving at 5 RPM to expose each sample to an averaged irradiance minimizing bulb-to-bulb differences in radiative output and fan cooled to ensure solution temperatures did not exceed $35^{\circ} \mathrm{C}$. The flux from the bulbs was measured by ferrioxalate actinometry and found to be $1.38 \pm 0.16 \times 10^{-5}$ milli-Einsteins $\mathrm{cm}^{-2} \mathrm{~s}^{-1}$ using Ferrozine ${ }^{\mathrm{TM}}$ instead of the typical phenanthroline complex to decrease equilibration time (see SI for in depth discussion) [12,22]. Nominally 1 part-per-million solutions of NQ, DNAN, and NTO were prepared in the various matrices by dilution of the stock solutions of the individual munitions in DI water in which the final volume of the experimental solution comprised $<0.1 \%$ of each stock to avoid significant dilution of the matrices. The concentration of each solution was determined by comparison with standards made in house for NTO and DNAN or against a commercially available standard for NQ (Restek) by HPLC. $5.00 \mathrm{~mL}$ of IM constituent solution was added via micropipette to a series of quartz test tubes (Technical Glass, $1.18 \mathrm{~cm}$ ID) which were arranged in the outer ring of the carousel. Irradiation times were carefully controlled with timer controller (The Control Co., 5090) and a sample taken by removing a tube at each interval. Degradation was monitored by HPLC (See Fig. S8-10).

\subsection{Environmental photolysis experiments}

Outdoor photolysis experiments were conducted in accordance with EPA method 835-2210 using quartz test tubes with Teflon lined septum screw caps (LuzChem, $11.11 \mathrm{~mm}$ ID, $\sim 13 \mathrm{~mL}$ capacity) on a matte black sample holder to incline the sample $30^{\circ}$ from the horizontal with the top of the samples pointed due North. All samples were prepared in the laboratory prior to transport to an experimental field stand $\left(\sim 20^{\prime}\right.$ high) covered in foil. In the quantum yield determinations, samples were prepared under a red laboratory light to avoid photolysis of the PNAP-PYR actinometer solutions.

\subsection{Computational chemistry}

The experimental results for NTO photolysis raised discussion points warranting validation of some of the properties and structure of the molecule. The various tautomers and isomers of NTO were optimized and evaluated using Gaussian16 [24] with MP2 method [25] and a ccpVTZ basis set [26]. Solvation effects were taken into account implicitly through the CPCM model [27] using a dielectric of 78.135 for water. Frequency calculations were done in order to determine the thermal contributions to the energy. NMR spectra was predicted via the GIAO method [28]. NBO analysis [29] was performed on the optimized structures to characterize the bonding nature. Heteroaromaticity was calculated by the HOMA method [30] as well as using Dr. Bird's unified aromaticity index and associated resonance energy [31a,31b].

\section{Photolysis rate theory and calculations}

Estimation of the maximum rate constant, Eq. (1), and minimum half-life, Eq. (2), were used to determine the applicability of the IMX101 constituents for further testing. 
$k=\Phi_{\lambda} \sum \varepsilon_{c \lambda} L_{\lambda}$

Where $\Phi_{\lambda}$ is the quantum yield as a function of wavelength, which in the instance of estimating maximum rate constants, was assumed to be unity, $\varepsilon_{c \lambda}$ absorption coefficient values $\left(\mathrm{M}^{-1} \mathrm{~cm}^{-1}\right)$ from the experimental determination of the molar absorption coefficient were averaged about a given wavelength (e.g., $\varepsilon_{297.5}=\left(\varepsilon_{297}+\varepsilon_{298}\right) / 2$ ) or taken as the molar absorption coefficient when the wavelength was an integer value, and the average solar radiation at Earth's surface $L_{\lambda}$ were taken from the EPA method 835-2210.

$t_{1 / 2}=\ln 2 / k$

Where $k$ was the theoretical maximum rate constant determined in Eq. (1), for minimum half-life calculations, or the experimentally determined rate constant, for definitive half-life determinations.

To determine the quantum yield of the individual munition constituents, $\Phi_{c}$, relative to the PNAP-PYR actinometer the rate constant, $k$, of the photolysis of the individual constituents was determined experimentally using Eq. (3),

$-k t=\ln [c]_{t} /[c]_{0}$

Where $[c]_{t}$ and $[c]_{0}$ are the analytically determined concentrations at the time the sample was taken and the initial experimental concentration, respectively. The rate constant, $k$, was determined by linear regression of the plot $\ln [c]_{t} /[c]_{0}$ against time measured in days.

To determine the concentration of pyridine in the PNAP-PRY actinometer Eq. (4) was used to first estimate the quantum yield, $\Phi_{a}$, necessary to closely match the rate constants of each IM constituent.

$\Phi_{a}=k / \sum \varepsilon_{a \lambda} L_{\lambda}$

Where $k$ was the experimentally determined rate constant for each individual munition constituent in the preliminary experiments and $\sum \varepsilon_{a \lambda} L_{\lambda}$ was the constant 551 taken from the EPA method 835-2210. With the estimated quantum yield for the actinometer, Eq. (5) was used to determine the concentration of pyridine needed.

$[P Y R]=\Phi_{a} / 0.0169$

To determine the quantum yields of the individual munition constituents from simultaneously irradiated samples of munition and PNAP-PYR actinometer Eq. (6) was used

$\Phi_{c}=k_{c} / k_{a} \times \sum \varepsilon_{a \lambda} L_{\lambda} / \sum \varepsilon_{c \lambda} L_{\lambda} \times \Phi_{a}$

Where $k_{c}$ and $k_{a}$ are the experimentally determined rate constants from plots derived from Eq. (3), $\sum \varepsilon_{a \lambda} L_{\lambda}$ is again the constant 551 from the EPA method, $\sum \varepsilon_{c \lambda} L_{\lambda}$ is the value calculated in Eq. (1) for each munition constituent, and $\Phi_{a}$ is the concentration dependent quantum yield of the actinometer determined for each IM constituent in Eq. (5).

Quantum yields for the indoor experiments were also estimated for the indoor exposures using Eq. (7)

$\Phi_{c}=k[I M]_{0} V /(I \times F \times S A)$

Where $k$ is the rate constant, $[\mathrm{IM}]_{0}$ is the starting molar concentration of the IM constituent, $\mathrm{V}$ is the volume irradiated, I is the radiant flux determined by ferrioxalate actinometry, $\mathrm{F}$ is the fraction of light absorbed by the IM constituent at the initial concentration from the BeerLambert Law $F=100-\% T=10^{-\varepsilon l c}$, and SA is the surface area of the reaction vessel exposed to irradiation.

\section{Results}

\subsection{Tier 1 testing}

The UV-vis spectra for each of the three constituents were recorded in triplicate at multiple aqueous concentrations to determine the molar absorption coefficient, and are depicted in Fig. 1. All spectra were recorded in triplicate at a given concentration and the molar absorption

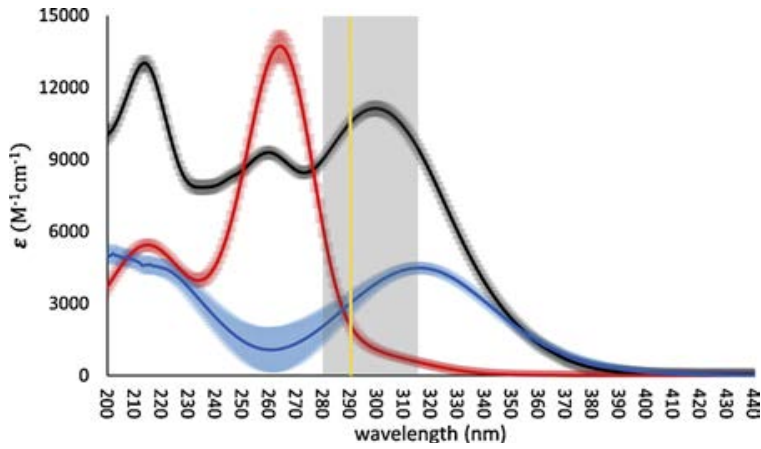

Fig. 1. UV-vis absorption coefficient spectra of IM constituents NQ (red), DNAN (black), and NTO (blue). Error bars represent the standard deviation for molar absorption coefficients determined at 3 different concentrations. The gray shaded area represents the emission range of the laboratory light source (full width half height) and the yellow line indicates the maximal energy, shortest wavelength, of sunlight reaching Earth's surface.

coefficients averaged over 3 concentrations (NQ, 15, 10, 7.5 ppm; DNAN, 20, 10, 5 ppm; NTO, 15, 10, 7.5 ppm). For DNAN and NQ the solvent was high purity water, and for NTO a dilute phosphate buffer was used to maintain the $\mathrm{pH}$ circumneutral for each spectra. The standard deviation of the molar absorption coefficient are also plotted.

\subsection{Outdoor photolysis experiments}

Outdoor photolysis experiments of the three munition constituents and the determination of their quantum yields is shown in Fig. 2. The slopes of the lines in Fig. 2B deviate from unity due to poor estimation of the rate constants and half-lives of the IM constituents based on preliminary outdoor photolysis tests.

\subsection{Matrix effect experiments}

To probe the effects environmentally relevant matrices would exhibit on the rates of photolysis, experiments were conducted in a laboratory setting. A photochemical reactor with a carousel allowed for a more direct comparison of the matrix effects, due to the difficulty in making comparisons for experiments conducted under different solar irradiation conditions and the logistical challenge of undertaking many experiments simultaneously. The photolysis for the IM constituents in the laboratory followed first order kinetics in each matrix, and the rate constants for each of the munitions in the various matrices is shown in Table 1.

\subsection{Computational NTO results}

In order to evaluate the preferred isomeric topology of NTO eight different protonation schemes were modeled to evaluate all plausible combinations of hydrogen locations around the primary molecular structure. Full results can be found in the SI (Tables S1 and S2). The 3 lowest energy forms are depicted in Fig. 3 with 'a' being the preferred protonation below it's $\mathrm{pK}_{\mathrm{a}}$ value of 3.7 , ' $\mathrm{b}$ ' the preferred protonation in neutral and basic conditions, and ' $c$ ' being the secondary isomer in acidic conditions. Isomer ' $\mathrm{c}$ ' is $3.0 \mathrm{kcal} / \mathrm{mol}$ disfavored compared to isomer ' $a$ ' and accordingly even in acidic conditions less than $1 \%$ of NTO molecules are expected to be in protonation state ' $c$ ' at room temperature. According to both the Bird and HOMA methods isomer ' $\mathrm{a}$ ' is somewhat less aromatic than the anionic isomer ' $\mathrm{b}$ '. As $\mathrm{pH}$ is lowered the distribution NTO forms switches from primarily ' $b$ ' to primarily ' $a$ ' thus we expect a decrease in aromaticity in more acidic conditions, which may explain the retardation of the photolytic kinetics at lower $\mathrm{pH}$ values. 

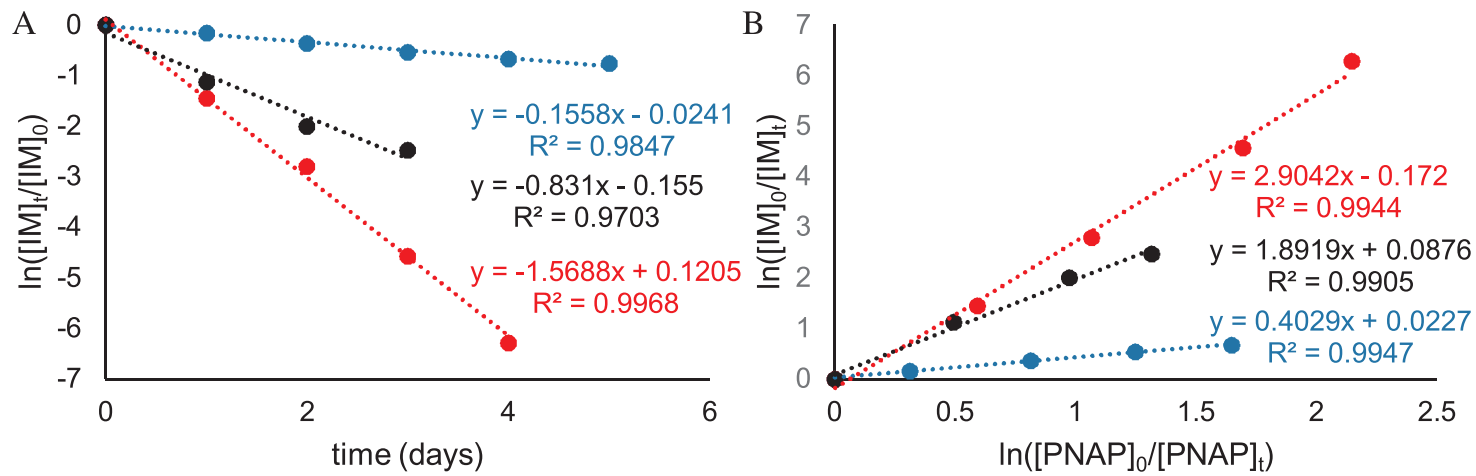

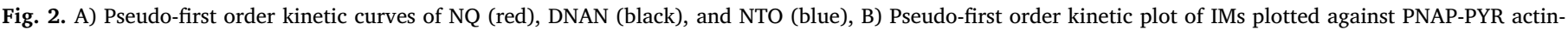

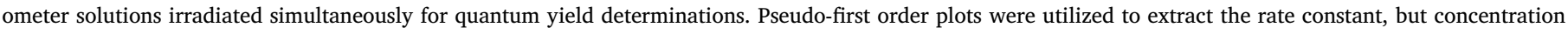
plots are available in the SI (Fig. S7).

Table 1

Rate constants of IMX-101 constitutents photolysis in different matrices. All rate constants are psuedo-first order with units of $\mathrm{min}^{-1}$. Rate constants were determined as the negative slope of the linear line through the average of 3 data points $\left(\ln [\mathrm{IM}]_{\mathrm{t}} /[\mathrm{IM}]_{0}\right)$ at each sampling interval (Fig. S11-43). Errors were calculated by linear regression and taken as the standard error of the slope.

\begin{tabular}{llll}
\hline Matrix & NQ & DNAN & NTO \\
\hline DI $\mathrm{H}_{2} \mathrm{O}$ & $1.17 \pm 0.05$ & $0.0206 \pm 0.00023$ & $0.0102 \pm 0.0005$ \\
humic acid & $0.445 \pm .020$ & $0.00842 \pm 0.00035$ & $0.0105 \pm 0.0005$ \\
MHRW & $0.988 \pm .028$ & $0.0199 \pm 0.0002$ & $0.00763 \pm 0.00018$ \\
brackish & $0.989 \pm 0.042$ & $0.283 \pm 0.005$ & $0.0131 \pm 0.0006$ \\
artificial ocean & $1.04 \pm 0.05$ & $0.438 \pm 0.017$ & $0.0255 \pm 0.0008$ \\
$1 \mathrm{M} \mathrm{NaCl}$ & $1.19 \pm 0.03$ & $0.520 \pm 0.006$ & $0.00768 \pm 0.00037$ \\
$0.1 \mathrm{M} \mathrm{NaCl}$ & $1.10 \pm 0.03$ & $0.138 \pm 0.003$ & $0.0143 \pm 0.0010$ \\
$0.01 \mathrm{M} \mathrm{NaCl}$ & $1.12 \pm 0.03$ & $0.0352 \pm 0.0008$ & $0.0102 \pm 0.0005$ \\
pH 4 & $1.07 \pm 0.04$ & $0.0250 \pm 0.0012$ & $0.0384 \pm 0.0032$ \\
pH 7 & $1.04 \pm 0.05$ & $0.0198 \pm 0.0002$ & $0.00768 \pm 0.00037$ \\
pH 10 & $1.19 \pm 0.03$ & $0.0240 \pm 0.0003$ & $0.0105 \pm 0.0006$ \\
\hline
\end{tabular}

\section{Discussion}

Using the molar absorptivity above $290 \mathrm{~nm}$ for each IM constituent the theoretical minimum half-lives (Eqs. (1 and 2)) were estimated, which for summer at $30^{\circ} \mathrm{N}$ (the latitude closest to the experimental station for which data is available) were $6.2 \times 10^{-3}$, and $0.20 \times 10^{-3}$, and $0.32 \times 10^{-3}$ days for NQ, DNAN, and NTO, respectively. The standard deviation in the UV-vis spectra were greater for NTO when compared to the other two munition constituents, potentially due to the lower pKa of the molecule [23]. As the concentration of NTO increases in the cuvette, the $\mathrm{pH}$ is lowered resulting in a new equilibrium distribution despite the use of a buffer solution. The theoretical minimum half-lives for each IM constituent were sufficiently low (i.e., < 30 days) to warrant further photolysis testing.

In the initial outdoor experimentation to estimate the photolysis kinetics of all three munitions were expected to follow a 1st order approximation. This was not clearly evident in the preliminary tests due to cloud cover during the NQ experiment, and poor estimation of sampling intervals based on literature regarding the other two constituents. The quantum yield value for DNAN, $1.1 \times 10^{-4}$ [12], corresponds to a halflife of 1.8 days using Eqs. ( 1 and 2) and substituting 3390 for the $\sum \varepsilon_{a \lambda} L_{\lambda}$ term in Eq. (1), whereas the published half-life was 0.70 days [12]. Literature reports show NTO is recalcitrant towards photolytic degradation [11]. The preliminary experiments for the three munitions gave rate constants $0.484,1.17$, and 0.811 day $^{-1}$ for NQ, DNAN, and NTO respectively. Control samples wrapped in foil resulted in no appreciable decrease in concentration for any of the IM constituents due to thermal reactions (e.g., hydrolysis). These rate constants corresponded to pyridine concentrations of $46.6 \mathrm{mM}, 57 \mathrm{mM}$, and $39.5 \mathrm{mM}$ for each of the PNAP-PYR actinometers for NQ, DNAN, and NTO respectively, using Eqs. (4 and 5). The definitive determination of the kinetics and quantum yields were conducted from June 9 to June 13, 2018 for DNAN and NTO and from June 25 to June 30, 2018 for NQ (Fig. 2).

From the experimentally determined rate constants in the definitive tests it was found the half-lives of the IM constituents to be $0.44,0.83$, and 4.4 days for NQ, DNAN, and NTO respectively. Although each

\section{a) neutral major form}

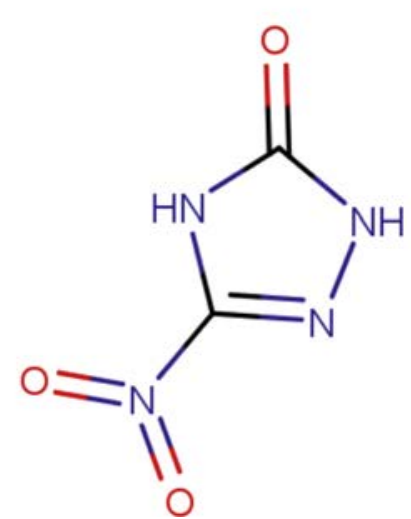

b) anionic form

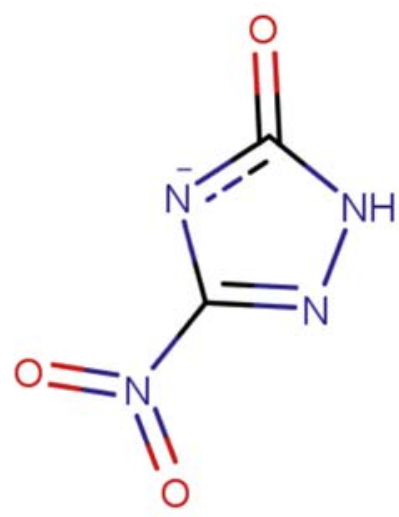

\section{c) neutral minor form}

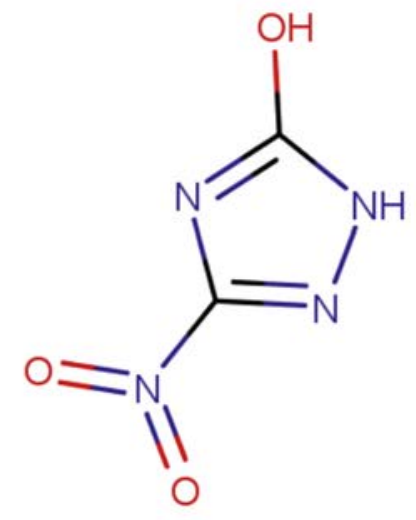

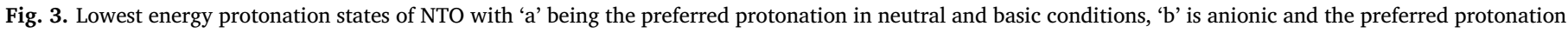
below $\mathrm{pH}$ 3.7, and 'c' being the secondary isomer in neutral and basic conditions. 
experiment was set outside for 5 days, DNAN was not present in a detectable concentration ([DNAN] < LOD) after the first 3 days and NQ after 4 days. When compared against their respective actinometer solutions the quantum yields for each of the IM constituents was found to be $1.0 \times 10^{-2}, 3.2 \times 10^{-3}$, and $5.9 \times 10^{-5}$ for NQ, DNAN, and NTO respectively. The half-life and quantum yield of NQ is in excellent agreement with the value matching those determined previously $[13,14]$, but the quantum yield of DNAN is 29 times greater than literature value [12]. The value found in the literature was determined in a solar simulator, at possibly a greater than recommended test chemical concentration and determined by calculations involving manufacturer supplied irradiance data [12]. The literature value for the quantum yield of DNAN is likely underestimated, as irradiance data supplied by manufacturers may differ from experimentally determined values [33].

Additionally, the photolysis of NTO warrants further study. These experiments were carried out in accordance with EPA method 835-2210 which is the standard way to determine direct photolysis and results indicate NTO does directly photolyze. This is in contrast to previous literature that has reported that the molecule does not undergo direct photolysis, but is susceptible to degradation by hydroxyl radicals or other reactive oxygen species (ROS) generated from photocatalysis and the Fenton reaction [11]. The rates of degradation by the ROS may be overestimated in light of the direct photolysis of NTO determined in this study; however the overestimation is undoubtedly slight due to the three order of magnitude greater starting concentrations than in the present study.

Based on the experimental results for the various matrices tested, little effect on the rate of NQ photolysis was observed, with the exception of the experiments conducted in the humic acid solution. The retardation of the reaction kinetics in humic acid solutions has been reported by others and is likely due to the competition for photon absorption $[13,14]$ and evidence NQ degrades via the singlet excited state. The lack of any significant difference in the photolytic rate in the other matrices tested is due to the poor coordination with ionic constituents and the negligible pKa of the molecule.

Conversely, the other two IMs exhibited relatively large changes in their photolytic rates in different matrices. NTO has a greater rate constant near its pKa (3.7) due to a much greater proportion of the molecule being protonated [32]. The protonated NTO is shown to exhibit less aromatic character through computational examination of the natural bonding orbitals, and this decreased stability leads to a greater rate of degradation in comparison to the anionic form of NTO. The rather modest increase in the rate of photolysis at $\mathrm{pH} 10$ over the rate at $\mathrm{pH} 7$ is possibly due to coordination of the hydroxide with the ring allowing for a substitution of the nitro group on the excited molecule through an $\mathrm{S}_{\mathrm{N}} \mathrm{Ar}$ * mechanism. The increased rate is not due to base catalyzed hydrolysis, as the average concentration of the $t=0$ samples of the three trials was found to be constant within experimental error at $1.27 \pm 0.006 \mathrm{ppm}$. All three replicates of the photolysis were done from the same stock solution prepared prior to any photolysis experiments, and if hydrolysis were occurring the concentration would have diminished in the stock solution. The $\mathrm{pH}$ dependence on photolytic rates was observed by others [15], however, direct comparisons to these results is hampered by the different experimental parameters employed (radiation sources, temperature, reaction vessel, etc.). There was no rate enhancement due to the presence of organic matter as a triplet sensitizer observed in the present study in contrast to a literature report [15], which is likely due to the much lower concentration of organic matter employed in the present study (5 ppm DOM/3.33 ppm TOC compared to $60 \mathrm{ppm} \mathrm{OC)}$.

The $\mathrm{pH}$ effects of DNAN were much more modest than for NTO. Like NQ, DNAN is not readily ionizable [34]. The rate was enhanced for DNAN when a salt matrix was utilized. In the initial experiments using the synthetic MHRW, brackish, and artificial seawater the increase in the trend was immediately observed. To probe this effect further, experiments were conducted in $\mathrm{NaCl}$ solutions to reduce the number of confounding factors as the artificial seawater has many different ionic constituents (the $\mathrm{NaCl}$ matrix was also used for the other IMs, but no significant enhancement or retardation of the rates were found). Coordination of ionic constituents with electron deficient aromatic rings is a known phenomenon, and will bring the ion in proximity to facilitate the substitution of either the methoxy or nitro groups on the photoexcited DNAN [35]. The rate enhancement was found to be linear over the concentrations of $\mathrm{NaCl}$ used, particularly over from $0-0.1 \mathrm{M}$ where the rate increased by a factor of 0.171 for every 0.01 increase in $\mathrm{NaCl}$ molarity; however, this data set is not complete as only four definitive concentrations of $\mathrm{NaCl}(0-1 \mathrm{M})$ were used. A deviation from linearity was observed when incorporating the highest concentration, possibly be due to the saturation of the ring systems with the anions. If this is the case, there is potentially a maximum achievable enhancement due to the salinity of the solutions. The rate of DNAN photolysis was not enhanced by the humic acid, and the reaction was roughly half the rate of the DI $\mathrm{H}_{2} \mathrm{O}$ experiments. It is possible DNAN, at least to a small extent, reacts from its triplet state. Previous indirect photolysis experiments did not show any significant change in the rate, but a much greater concentration of humic acid was used than in the present study [15]. If the triplet-triplet transfer was favored by the roughly 10 fold increase in humic acid concentration this could have offset the competition for photons leading to a decreased degradation rate observed here.

Direct comparisons to published literature can be made from the experiments with DNAN due to the similarity of light sources employed $\left(1.4 \times 10^{-4}\right.$ milli-Einsteins $\mathrm{cm}^{-2} \mathrm{~s}^{-1}$ literature, $1.38 \times 10^{-4}$ milliEinsteins $\mathrm{cm}^{-2} \mathrm{~s}^{-1}$ present study). DNAN was previously found to photolyze under UV-B irradiation (predominately from 280 to $315 \mathrm{~nm}$ based on FWHM from manufacturer information (see Fig. S3) at a rate of $6.57 \pm 0.15 \mathrm{~d}^{-1}[12]$, whereas in the present study the rate constant was $29.7 \pm 0.3 \mathrm{~d}^{-1}$. The discrepancy between the published results and the present study is likely due to the differing reaction vessels and photochemical reactor designs. In the present study light entered quartz test tubes from all sides as samples rotated in a carousel and in the literature account light only entered from a single side of a quartz cuvette (not accounting for scattering by the reactor's unpolished surfaces), where the ratio of the given surface areas for the reaction vessels is 5.4. This factor very nearly accounts for the difference in the rate constants.

Direct comparison to the published result for the quantum yield of DNAN under UV-B irradiation, $\Phi_{U V-B}=3.7 \times 10^{-4}$, is not possible due to the method in which this result was calculated; however, using the results from their ferrioxalate actinometry experiments in equation and experimental parameters (e.g., surface area) in Eq. (7) these values can be estimated. The values can only be estimated due to the rather favorable overlap of the emission spectrum from the irradiation source and an absorption maximum for DNAN in the same range where the average molar absorption coefficient and standard deviation is $10406 \pm 640 \mathrm{M}^{-1} \mathrm{~cm}^{-1}$ (this is not the case for NQ nor NTO where the standard deviation represents an error of roughly 100\%). With the above caveat in mind, the quantum yields for the published data and the present study, respectively, are $2.41 \times 10^{-4}$ and $2.93 \times 10^{-4}$.

The discrepancies between the present study and the published literature for the photolysis of DNAN would also benefit from a third party investigation. Although the half-life of the molecule found here, $0.83 \mathrm{~d}$, is in good agreement with the previous study, $0.7 \mathrm{~d}$, there is a factor of 29 times greater quantum yield measured here for the outdoor experiments. This difference is likely due to the means in which the value was calculated based on radiometry in the UV range rather than simultaneously exposing an actinometer solution [12]. Comparison of the UV-B quantum yield of DNAN with the aforementioned study gave comparable results with the measured value here being $22 \%$ greater, likely due to slight differences in the emissions from the irradiation sources, reactor design, and reaction vessels. 


\section{Conclusions}

The environmentally relevant rate constants and half-lives of the three IM constituents NQ, DNAN, and NTO have been determined using natural sunlight and a laboratory photochemical reactor finding direct photolysis of the IM constituents to be rapid. The quantum yields of these compounds were also determined with excellent agreement compared to literature values for NQ, disparate values for DNAN, and the first reported values for NTO were measured. Further understanding of the environmental fate of these IM constituents was undertaken by incorporation of environmentally relevant matrices, particularly important for the highly water soluble NQ and NTO. The magnitude of the rate constants varied in the laboratory experiments from those conducted under solar irradiation due to the laboratory source emitting from $\sim 280-315 \mathrm{~nm}$ greatly increasing the number of photons absorbed by NQ (see Fig. 1). Salt concentrations were found to dramatically increase the rate of photolysis for DNAN, and NTO was sensitive to changes in $\mathrm{pH}$ due to its lower pKa. NQ was not found to have significant enhancement, but was slower to photolyze when humic acid was incorporated into the matrix. Further investigations into the photochemical kinetics and quantum yields for NTO and DNAN are warranted based on literature discrepancies, whereas NQ had very similar kinetics and quantum yield values compared to published results. Finding values for NTO relevant to the chemical's fate (i.e., $t_{1}$ ${ }_{2}<30$ d) necessitates more study to inform stakeholders of the potential for photolysis at environmentally relevant time scales and concentrations.

\section{Acknowledgments}

The use of trade, product or firm names in this report is for descriptive purposes only and does not imply endorsement by the U.S. Government. The tests described and the resulting data presented herein were obtained from research conducted under the Environmental Quality and Technology Program of the United States Army Corps of Engineers by the USAERDC (WIC H2735L). Permission was granted by the Chief of Engineers and PEO AMMO to publish this information. The findings of this report are not to be construed as an official Department of the Army position unless so designated by other authorized documents. The authors also thank Dr. Anthony Bednar for his review of this document.

\section{Appendix A. Supplementary data}

Supplementary material related to this article can be found, in the online version, at doi:https://doi.org/10.1016/j.jphotochem.2019. 112094.

\section{References}

1] K.E. Lee, W.A. Balas-Hummers, A.R. Di Stasio, C.H. Patel, J. Samuels, Qualification testing of the insensitive TNT replacement explosive IMX-101, Proceedings, 2010 Insensitive Munitions \& Energetic Materials Technology Symposium, Munich, Germany, October 11-14, 2010, pp. 1-13.

[2] W. McBride, R.A. Henry, J. Cohen, S. Skolnik, Solubility of Nitroguanidine in water, J. Am. Chem. Soc. 73 (1) (1951) 485-486.

[3] S. Taylor, E. Park, K. Bullion, K. Dontsova, Dissolution of three insensitive munitions formulations, Chemosphere 119 (2015) 342-348.

[4] A.J. Kennedy, A.R. Poda, M.L. Melby, L.C. Moores, S.M. Jordan, K.A. Gust, A.J. Bednar, Aquatic toxicity of photodegraded insensitive munition 101 (IMX-101) constituents, Envron. Toxicol Chem. 36 (2017) 2050-2057.

[5] W.H. van der Schalie, The Toxicity of Nitroguanidine and Photolyzed Nitroguanidine to Freshwater Organisms, Army Medical Bioengineering Research and Development Lab, Fort Detrick, MD, 1984, pp. 1-35. Technical Report: ADA153045. October 1982-April 1984.

[6] K.A. Gust, J.K. Stanley, M.S. Wilbanks, M.L. Mayo, P. Chappell, S.M. Jordan, L.C. Moores, A.J. Kennedy, N.D. Barker, The increased toxicity of UV-degraded nitroguanidine and IMX-101 to zebrafish larvae: evidence implicating oxidative stress, Aquat. Toxicol. 190 (2017) 228-245.

[7] A. Halasz, J. Hawari, N.N. Perreault, New insights into the photochemical degradation of the insensitive munition formulation IMX-101 in water, Env. Sci.
Technol. 52 (2) (2018) 589-596.

[8] J. Hawari, F. Monteil-Rivera, N.N. Perreault, A. Halasz, L. Paquet, Z. Radovic Hrapovic, S. Deschamps, S. Thiboutot, G. Ampleman, Environmental fate of 2,4 dinitroanisole (DNAN) and its reduced products, Chemosphere 119 (2015) 16-23.

[9] C.I. Noss, R.H. Chyreck, Nitroguanidine Watewater Pollution Control Tehnology: Phase III. Treatment With Ultraviolet Radiation, Ozone, and Hydrogen Peroxide, US Army Medical Bioengineering Research and Development Laboratory, Fort Detrick, MD, 1984, pp. 1-28. Technical Report ADA139389. September 1983-December 1983.

[10] W.D. Burrows, M.O. Schmidt, R.H. Chyrek, C.I. Noss, Photochemistry of Aqueous Nitroguanidine, U.S. Army Biomedical Research and Development Laboratory, Fort Detrick, MD, 1988, pp. 1-28. Technical Report ADA203200. October 1984-September 1986.0.

[11] L. Le Campion, C. Giannotti, J. Ouazzani, Photocatalytic degradation of 5-Nitro1,2,4-Triazol-3-One NTO in aqueous suspention of $\mathrm{TiO}_{2}$. Comparison with fenton oxidation, Chemosphere 38 (7) (1999) 1561-1570.

[12] B. Rao, W. Wang, Q. Cai, T. Anderson, B. Gu, Photochemical transformation of the insensitive munitions compound 2,4-dinitroanisole, Sci. Tot. Env. 443 (2013) 692-699.

[13] R.J. panggord, T.W. Chou, T. Mill, W. Haag, W. Lau, Environmental Fate of Nitroguanidine, Diethyleneglycol Dintrate, and Hexachloroethane Smoke, SRI International, Menlo Park, CA, 1987, pp. 1-67. Technical Report ADA200324. May 1986-Aprul 1987.

[14] W.R. Haag, R. Spanggord, T. Mill, R.T. Podoll, T.-W. Chou, D.S. Tse, J. Harper, Aquatic environmental fate of nitroguanidine, Env. Toxicol. Chem. 9 (1990) 1359-1367.

[15] K. Dontsova, S. Taylor, R. Pesce-Rodrigues, M. Brusseau, J. Arthur, N. Mark, M. Walsh, J. Lever, J. Šimůnek, Dissolution of NTO, DNAN, and Insensitive Munitions Formulations and Their Fates in Soils, U.S. Army Corps of Engineers, Cold Regions Research and Engineering Laboratory, Hanover, NH, 2014, pp. 1-92. Technical Report TR-14-23. September.

[16] G.G. Wubbles, H. Danian, D. Policarpio, Temperature Dependence of Regioselectivity in Nucleophilic Photosubstitution of 4-Nitroanisole. The Activation Energy Criterion for Regioselectivity, J. Org. Chem. 75 (22) (2010) 7726-7733.

[17] R.L. Lettsinger, O.B. Ramsay, J.H. McCain, photoinduced substitution. II. substituent effects in nucleophilic displacement on substituted nitrobenzenes, J. Am. Chem. Soc. 87 (13) (1965) 2945-2953.

[18] R.L. Lettsinger, J.H. McCain, Photoreactions of nitroanisoles with cyanide Ion. Studies of products and reaction sequence, J. Am. Chem. Soc. 91 (23) (1969) 6425-6431.

[19] D.W. O'Sullivan, J.R. Denzel, D.J. Luning Prak, Photolysis of 2,4,6-trinitrotoluene in seawater: effect of salinity and nitrate concentration. Environmental chemistry of explosives and propellant compounds in soils and Marine systems: distributed source characterization and remedial technologies, American Chemical Society Symposium Series Vol. 1069 (2011).

[20] US EPA method 835-2210, Direct Photolysis Rate in Water by Sunlight, EPA 712-C98-060; Washington, DC (1998), pp. 1-35.

[21] US EPA method 821/R-02/012, Methods for Measuring the Acute Toxicity of Effluents and Receiving Waters to Freshwater and Marine Organisms, 5th ed., Office of Water, Washington DC, 2002.

[22] S. Goldstein, J. Rabani, The ferrioxalate and iodide - iodate actinometers in the UV region, J. Photochem. Photobiol. A: Chem. 193 (2008) 50-55.

[23] W.M. Haynes, D.R. Lide, T.J. Bruno, CRC Handbook of Chemistry and Physics: a Ready-reference Book of Chemical and Physical Data, 2010, 91st ed., CRC Press, Boca Raton, Florida, 2011.

[24] M.J. Frisch, G.W. Trucks, H.B. Schlegel, G.E. Scuseria, M.A. Robb, J.R. Cheeseman, G. Scalmani, V. Barone, G.A. Petersson, H. Nakatsuji, X. Li, M. Caricato, A.V. Marenich, et al., Gaussian16, Revision B.01, Gaussian Inc., Wallingford CT, 2016.

[25] C. Møller, M.S. Plesset, Note on an approximation treatment for many-electron systems, Phys. Rev. 46 (7) (1934) 618-622.

[26] T.H. Dunning Jr., Gaussian basis sets for use in correlated molecular calculations. 1. The atoms boron through neon and hydrogen, J. Chem. Phys. 90 (1989) 1007-1023.

[27] V. Barone, M. Cossi, Quantum calculation of molecular energies and energy gradients in solution by a conductor solvent model, J. Phys. Chem. A 102 (1998) 1995-2001, https://doi.org/10.1021/jp9716997.

[28] F. London, The quantic theory of inter-atomic currents in aromatic combinations, J. Phys. Radium 8 (1937) 397-409, https://doi.org/10.1051/ jphysrad:01937008010039700.

[29] J.P. Foster, F. Weinhold, Natural hybrid orbitals, J. Am. Chem. Soc. 102 (1980) 7211-7218, https://doi.org/10.1021/ja00544a007.

[30] M.K. Cyranski, Energetic aspects energetic aspects of cyclic pi-electron delocalization: evaluation of the methods of estimating aromatic stabilization energies, Chem. Rev. 105 (2005) 3773-3811.

[31] (a) C.W. Bird, Heteroaromticity. A unified aromaticity index, Tetrahedron 3 (2) (1992) 335440

(b) C.W. Bird, A new aromaticity index and its application to five-membered ring heterocycles, Tetrahedron 41 (7) (1985) 1409-1414.

[32] L. Le Campion, M.T. Adeline, J. Ouazzani, Separation of NTO related 1,2,4-Triazole3-One derivatives by a high performace liqiud chromatography and capillary electrophoresis, Propellants Explos. Pyrotech. 22 (1997) 233-237.

[33] E. Asenath-Smith, E. Ambrogi, L.C. Moores, S.D. Newman, J.A. Brame, Leveraging chemical actinometry and optical radiometry to reduce uncertainty in photochemical research, J. Photochem. Photobiol. A: Chem. 372 (2019) 279-287.

[34] D.H. Ripin, D.A. Evans, http://evans.rc.fas.harvard.edu/pdf/evans_pKa_table.pdf (Accessed 30th September 2018).

[35] M. Mascal, A. Armstrong, Bartberger, M.D. Anion-aromatic bonding: a case for anion recognition by $\pi$-Acidic rings, J. Am. Chem. Soc. 124 (22) (2002) 6274-6276. 


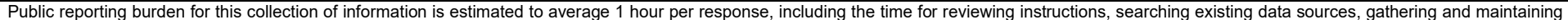

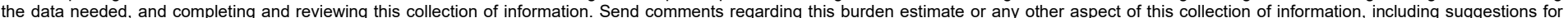

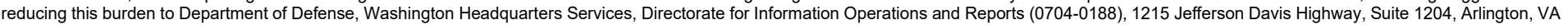

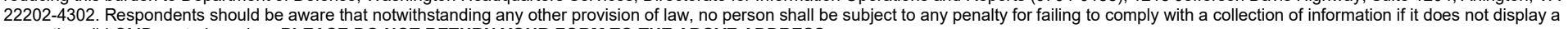
currently valid OMB control number. PLEASE DO NOT RETURN YOUR FORM TO THE ABOVE ADDRESS.
1. REPORT DATE (DD-MM-YYYY)
2. REPORT TYPE
September 2021 Final

\section{TITLE AND SUBTITLE}

Photo Degradation Kinetics of Insensitive Munitions Constituents Nitroguanidine,

Nitrotriazolone, and Dinitroanisole in Natural Waters

\section{AUTHOR(S)}

Lee C. Moores, Stacy J. Jones, Garrett W. George, David L. Henderson, and

Timothy C. Schutt

\section{PERFORMING ORGANIZATION NAME(S) AND ADDRESS(ES)}

Environmental Laboratory

U.S. Army Engineer Research and Development Center

3909 Halls Ferry Road

Vicksburg, MS 39180

9. SPONSORING / MONITORING AGENCY NAME(S) AND ADDRESS(ES)

U.S. Army Corps of Engineers

Washington, DC 20314
HX5

212 Eglin Parkway SE

Ft. Walton Beach, FL 32548
3. DATES COVERED (From - To)

5a. CONTRACT NUMBER

5b. GRANT NUMBER

5c. PROGRAM ELEMENT NUMBER

5d. PROJECT NUMBER

5e. TASK NUMBER

5f. WORK UNIT NUMBER

8. PERFORMING ORGANIZATION REPORT NUMBER

ERDC/EL MP-21-11

10. SPONSOR/MONITOR'S ACRONYM(S)

USACE

11. SPONSOR/MONITOR'S REPORT NUMBER(S)

\section{DISTRIBUTION / AVAILABILITY STATEMENT}

Approved for public release; distribution is unlimited.

\section{SUPPLEMENTARY NOTES}

This article was originally published online in the Journal of Photochemistry \& Photobiology A: Chemistry on 17 September 2019.

This project was supported under the USACE Environmental Quality and Technology Program and ERDC, WIC H2735L.

\section{ABSTRACT}

Herein the matrix effects on the kinetics of aqueous photolysis for the individual munitions constituents of IMX-101: nitroguanidine (NQ), dinitroanisole (DNAN), and nitrotriazolone (NTO) are reported along with the environmentally relevant kinetics and quantum yields. Photolysis potentially represents a major degradation pathway for these munitions in the environment and further understanding the complex matrices effects on photolytic kinetics was needed. Aqueous systems are of particular interest due to the high solubility of NQ (3,800 ppm) and NTO (16,642 ppm) compared to the traditional munitions trinitrotoluene (TNT, 100.5 ppm) and 1,3,5-trinitro-1,3,5-triazine (RDX, $59.9 \mathrm{ppm}$ ). Environmental half-lives (and quantum yields) were found to be 0.44 days, 0.83 days, and 4.4 days for NQ, DNAN, and NTO, respectively, under natural sunlight. In laboratory experiments using nominally $300 \mathrm{~nm}$ bulbs in a merry-go-round style reactor in DI water the relative rate of photolysis for the three munitions constituents followed the same order NQ > DNAN > NTO, where DNAN and NTO reacted 57 and 115 times more slowly, respectively, than NQ. In the various environmentally relevant matrices tested in the laboratory experiments NQ was not significantly affected, DNAN showed a faster degradation with increasing ionic strength, and NTO showed a modest salinity and pH dependence on its rate of photolysis.

\section{SUBJECT TERMS}

Dinitroanisole, Nitrotriazolone, Nitroguanidine, Photolysis, Quantum yield, Kinetics

\section{SECURITY CLASSIFICATION OF:}

\section{a. REPORT}

Unclassified

b. ABSTRACT
Unclassified

\section{c. THIS PAGE}

Unclassified

\begin{tabular}{c|c}
$\begin{array}{c}\text { 17. LIMITATION } \\
\text { OF ABSTRACT }\end{array}$ & $\begin{array}{c}\text { 18. NUMBER } \\
\text { OF PAGES }\end{array}$ \\
UU & 11 \\
\hline
\end{tabular}

19a. NAME OF RESPONSIBLE PERSON

19b. TELEPHONE NUMBER (include area code) 